\title{
Factors affecting behaviours that address HIV risk among Black and White South Africans
}

\author{
K Peltzer, Professor, Health Behaviour Research Unit, University of the North
}

\begin{abstract}
The aim of this study was to identify factors affecting HIV risk reduction among 150 Black and 150 White South Africans chosen by systematic random sampling.

Main outcome measures included sexual behavior and condom use, knowledge about correct condom use, intention of condom use, behavioural norms, attitudes, normative beliefs, and subjective norms about condoms, HIV/AIDS health beliefs, and HIV risk behaviour. Bivariate analysis gave positive significant relations among being single, age, HIV/ AIDS perceived severity, HIV/AIDS prevention barriers and HIV risk behaviour. Further, bivariate analysis gave negative significant relations among age at onset of puberty, age at first vaginal intercourse, correct condom use knowledge, subjective norms, intention to use condoms and HIV risk behaviour. Regression analysis indicated that for subjective norm to use condoms, less intention for condom use, less condom use knowledge and younger age of first vaginal intercourse were predictive for HIV/AIDS risk behaviour. HIV prevention intervention programmes should include the identified factors and cultural diversity.
\end{abstract}

\section{Introduction}

\section{Problem statement}

Abdool Karim and Abdool Karim (2000: 3) indicate that the annual national antenatal HIV seroprevalence rate in South Africa rose more than 21-fold from 1990 (0.76\%) to 1997 (16.01\%). It is expected that the prevalence of AIDS will reach about $27 \%$ of the sexually active population in South Africa by the year 2010 (Webb 1997: 214).

Condoms are an integral part of STD and HIV/AIDS prevention, and their use has increased significantly over the past decade. Correct use of condoms reduces the risk of HIV transmission by almost 100 percent. Therefore, condom promotion has received considerable attention in the fight against the AIDS pandemic (World Health Organisation, 1995: 3ff.). Yet condom use is among the most difficult issues to address in designing programmes to reduce the sexual transmission of HIV in Africa. Campbell (1997: 187) summarizes for sub-Saharan Africa that negative attitudes toward condom use are often based on cultural factors, e.g. the desire for children and female sexual compliance as ways to achieve economic status. Among Tanzanian adults it was found that $320(20.6 \%)$ reported having ever used a condom and of the 320 respondents who had ever used a condom, $34(10.6 \%)$ reported having used it at the last sexual intercourse (Mnyika, Klepp, Kvale, Schreiner \& Seha 1997: 176).

In South Africa, aversion to condom use is the dominant theme, although explanations for this vary; cultural beliefs are also a barrier to condom use in South Africa, where many people consider it essential that the sperms of the men actually enters the woman (Gould 1993: 132f.). All in a sample of 100 urban black mothers questioned in Durban stated that they had never experienced sexual intercourse where their partner had used a condom (Abdool Karim, Abdool-Karim \& Nkomokazi, 1991; 340). The highest incidence of condom use was in a sample of gold miners, where $32.6 \%$ had used them at least once (Ijsselmuiden, Padayachee, Mashaba, Martini \& Van Staden, 1990: 520). Kirigia and Muthuri (1999: 488) found that white South African women have a higher likelihood of asking their new sexual partners to use condoms than their African, Coloured and Indian counterparts, indicating cultural diversity in factors affecting condom use.

\section{Rational}

In order to design effective education and other interventions to reduce risk, it is not only important to know what the knowledge, beliefs, and risk behaviours are, but also to know what factors are associated with these risk behaviours (Mathai, Ross, \& Hira 1997: 563). One's risk of HIV infection is a function of the number of partners one has, the behaviours one engages in with those partners (such as sexual intercourse without use of a condom), the probability that those partners have HIV/ AIDS, and the transmissibility of the disease (Brunham \& Plummer 1990: 1339). Literature indicates that factors affecting HIV risk reduction are a range of situational, interpersonal and structural factors such as knowledge about AIDS, behavioral intention, perceived vulnerability, perceived barriers, self-efficacy, and demograhic factors (Basen-Engquist 1992: 120, Bengel, Belz-Merk \& Farin 1996: 505).

\section{Aim}

Since there was a lack of studies in South Africa, the purpose of this study was to identify factors affecting HIV risk reduction among Blacks and Whites in South Africa.

\section{Objectives}

-To identify the association between biographic factors, sexual 
history, health beliefs, condom use knowledge, behavioural and subjective norms to use condoms, normative beliefs to use condoms, attitudes towards condom use and condom use intention with HIV risk behaviour.

-To identify independent predictors for HIV risk behaviour.

\section{Methods}

\section{Design}

The study is an interview-administered telephone survey using a cross-sectional design.

\section{Sample and procedure}

The sample included 150 Blacks in a formerly Black area (township) and 150 Whites in a formerly White urban area in the Limpopo Province of South Africa.

Participants were chosen by a 1-a-30 systematic random telephone sampling, excluding nonresidential numbers, from the directory of one formerly Black and one formerly White area. A research assistant trained in interviewing made telephone calls until, in each sample, 150 participants- in the age range from 21 to 50 years- had been identified. Participants were assured of
Whites (51.4\%) (51 male and 63 female), in the age range of 21 to 50 years ( $M$ age 32.5 yr., $S D=6.7$ ) for Blacks and in the age range of 21 to 50 years ( $M$ age $32.3 \mathrm{yr}$., $S D=8.4$ ).

\section{Measures}

The questionnaire was pilot tested on 15 Black and 15 White adults, who did not form of the final sample. No modifications were required after pilot testing. The questionnaire consisted of questions about:

(a) Biographic data (6 items);

(b) Sexual activity and condom use (12 items);

(c) Knowledge of correct male condom use (10 items) (Sharma Dave, Sharma \& Chauhan, 1997: 711); Cronbach alpha as well as split-half reliability coefficients for condom knowledge scale were .62 and .59 for this sample.

(d) Intention of using condoms (when having sex next time with a new partner) ( 1 item) (from $-2=$ strongly agree to $+2=$-strongly disagree);

(e) Behavioral norm to use condoms (3 items), such as "Do you and your friends talk about using condoms?" (rated $1=$ Yes, - I=No, 0=Don't know);

(f) Attitudes towards condoms (3 items), such as "It is a good

\section{Table 1: Descriptive and bivariate analyses for the HIV/AIDS risk index}

\begin{tabular}{|l|l|l|l|}
\hline Variable & $\mathrm{M}$ & SD & Pearson Correlation $(r)$ \\
\hline 1. White (versus black) & & & -.158 \\
\hline 2. Female (versus male) & & & .076 \\
\hline 3. Single (versus married or steady partner) & & & $.210^{*}$ \\
\hline 4. Age & 32.4 & 7.5 & $.162^{*}$ \\
\hline 5. Age at onset of puberty & 14.2 & 2.2 & $-.254^{* *}$ \\
\hline 6. Age at first vaginal intercourse & 16.8 & 3.9 & $-.504^{* * *}$ \\
\hline 7. HIV/AIDS perceived susceptibility & 15.6 & 4.7 & -.106 \\
\hline 8. HIV/AIDS perceived severity & 19.3 & 4.7 & $.248^{* *}$ \\
\hline 9. HIV/AIDS perceived prevention benefits & 19.7 & 4.6 & -.006 \\
\hline 10. HIV/AIDS perceived prevention barriers & 14.3 & 4.5 & $.314^{* * *}$ \\
\hline 11. Correct condom use knowledge & 7.7 & 1.6 & $-.303^{* * *}$ \\
\hline 12. Behavioural norms to use condoms & 1.5 & 1.3 & -.012 \\
\hline 13. Attitudes towards condom use & .4 & 1.1 & .032 \\
\hline 14. Normative beliefs to use condoms & 2.1 & 3.9 & -.137 \\
\hline 15. Subjective norm to use condom & 1.2 & 1.2 & $-.388^{* * *}$ \\
\hline 16. Condom use intention & 1.2 & 1.2 & $-.433^{* * *}$ \\
\hline
\end{tabular}

(Items 13, 14, 15, 16 were reverse scored), $* * * p<.001, * * p<.01, * p<.05$

complete anonymity. They were told that their name was randomly selected from the telephone directory and that no names were written on the filled in questionnaires.

From the 300 participants 45 (15\%) opted against participation, and from the remaining 255 only those cases were analyzed who had had a (vaginal) sexual experience. These were in total 222 (87\%), 108 Blacks (48.6\%) (36 male and 72 female) and 114 idea for me to use condoms!" (rated from $-2=$ strongly agree to $+2=$ strongly disagree);

(g) Normative beliefs about condoms ( 3 items referring to parents, sex partners, close friends), such as "My partner thinks I should use condoms" (rated from $-2=$ strongly agree to $+2=$ strongly disagree);

(h) Subjective norms about condoms (Most people who are 
important to me think I should use condoms) ( 1 item) (rated from $-2=$ strongly agree to $+2=$ strongly disagree);

(i) A 16-item AIDS Health Belief Scale (AHBS), developed by Zagumny and Brady (1998: 173), to measure the four components of the Health Belief Model (HBM): perceived susceptibility to disease, perceived severity of a specific disease, perceived benefits of preventive behaviour, and barriers to preventive behaviour. Scaling involved the use of a 6-point Likert type scale with responses of "strongly agree" weighted 6 and "strongly disagree" weighted 1. For all sub-scales, higher scores represent a greater amount of that belief. Cronbach alpha as well as split-half reliability coefficients for the AIDS Health Belief Scale were .67 and .56 for this sample.

A HIV/AIDS risk index included the following items: (i) History of sexually transmitted disease, (ii) Had sex under the influence of alcohol, (iii) Frequency of vaginal sex during the last 3 months (without condom), (iv) Frequency of oral sex during the last 3 months without condom, (v) Frequency of anal sex during the last 3 months without condom, (vi) Number of sexual partners in the last 12 months, (vii) Frequency of vaginal intercourse in the past 3 months with a 'casual' partner and (viii) Frequency of vaginal intercourse in the past 3 months with a commercial sex worker.

\section{Results}

\section{Bivariate analysis}

Bivariate analysis indicated that being single, age, HIV/AIDS perceived severity as well as HIV/AIDS prevention barriers were positively associated, and age at onset of puberty, age at first vaginal intercourse, correct condom use knowledge, subjective norms as well as intention to use condoms were negatively associated with HIV risk behaviour. Culture, gender, HIV/ AIDS perceived susceptibility, perceived prevention benefits, behavioural norms, normative beliefs and attitudes towards condom use were not associated with HIV risk behaviour.

\section{Regression analysis}

Only the variables, which were correlated with the HIV/AIDS risk index, were included in the equation. Stepwise multiple regression analysis is shown in Table 2. tive of HIV/AIDS risk behaviour. The model accounted for $74 \%$ of the variance (adjusted $\mathrm{R}^{2}: .528$ ). Excluded from the equation were age, age at onset of puberty, perceived prevention barriers and perceived HIV/AIDS severity.

\section{Discussion and conclusion}

Subjective norm to use condoms ('Most people who are important to me think I should use condoms), condom use intention, correct condom use knowledge were inversely and younger age of first vaginal intercourse was predictive for HIV/ AIDS risk behaviour. This means the improvement of subjective norms to use condoms, condom use intentions and knowledge of correct condom use in HIV prevention programmes could lead to the reduction of HIV risk behaviour. The finding that age at first vaginal intercourse was negatively related to high risk behavior may be explained by factors such as an increase of the number and type of sexual partners, history of a sexually transmitted disease and frequency of sex with increasing age. Flisher, Ziervogel, Chalton, Leger and Robertson (1993: 596) state that age at first intercourse may be a poor indicator of risk owing to the possibility of a long time interval between the first and subsequent sexual encounters and infrequency of sexual intercourse.

In line with other literature it was found that factors affecting HIV risk reduction are a range of situational, interpersonal and structural factors such as knowledge about correct

condom use, behavioral intention, perceived severity, perceived prevention barriers, and demograhic factors (Basen-Engquist 1992: 120, Bengel, Belz-Merk \& Farin 1996: 505).

Further investigation is needed on factors associated with HIV risk behavior such as marital status, age, HIV/AIDS perceived severity, and perceived prevention barriers, and they should be included in HIV prevention intervention programmes.

\section{Acknowledgement}

The financial assistance of the National Research Foundation (South Africa) towards this research is hereby acknowledged. Opinions expressed this publication and conclusions arrived at, are those of the author and are not necessarily to be attributed to the National Research Foundation.

\section{Table 2: Regression analysis on HIV/AIDS risk index}

\begin{tabular}{|l|l|l|l|}
\hline Model 4 & Beta & $t$ & $p$ \\
\hline Subjective norm to use condoms & -436 & -6.440 & .000 \\
\hline Condom use intention & -.364 & -4.340 & .000 \\
\hline Condom use knowledge & -.269 & -3.708 & .000 \\
\hline Age at first vaginal intercourse & -.233 & -3.172 & .002 \\
\hline
\end{tabular}

Subjective norm to use condoms, intention of condom use, correct condom use knowledge were inversely predictive, whereas younger age of first vaginal intercourse was predic- 


\section{References}

ABDOOL KARIM, Q \& ABDOOL KARIM, SS 2000: Epidemiology of HIV in South Africa. Durban: Medical Research Council.

ABDOOL-KARIM, Q; ABDOOL-KARIM, SS \& NKOMOKAZI, J 1991: Sexual behaviour and knowledge of AIDS among urban Black mothers. South African Medical Journal. $80: 340-343$.

BASEN-ENGQUIST, K 1992: Psychosocial predictors of "safer sex" behaviors in young adults. AIDS Education \& Prevention. 4: 120-134.

BENGEL, J; BELZ-MERK, M \& FARIN, E 1996: The role of risk perception and efficacy cognitions in the prediction of HIV-related preventive behavior and condom use. Psychologv \& Health. 11:505-525.

BRUNHAM, R \& PLUMMER, F 1990: A general model of sexually transmitted disease epidemiology and its implications for control. Medical Clinics of North America. 74: 1339-1352.

CAMPBELL, T 1997: How can psychological theory help promote condom use in sub-Saharan African developing countries. Journal of the Royal Society of Health. 117: 186-191.

FLISHER, AJ; ZIERVOGEL, CF; CHALTON, DO; LEGER, PH \& ROBERTSON, BA 1993: Risk-taking behaviour of Cape Peninsula high-school students: Part VIII. Sexual behaviour. South African Medical Journal. 83: 595-597.

GOULD, P 1993: The slow plague. London: Blackwell.

IJSSELMUIDEN, CB; PADAYACHEE, GN; MASHABA, W; MARTINI, O \& VAN STADEN HP 1993: Knowledge, beliefs and practices among black goldminers relating to the transmission of HIV and other sexually transmitted disease. South African Medical Joumal. 78: 520-523.

KIRIGIA, JM \& MUTHURI, LHK 1999: Predictors of women's decision to ask new partners to use condoms to avoid HIV/ AIDS in South Africa. East African Medical Journal. 76: 484489.

MATHAI, R; ROSS, MW \& HIRA, S 1997: Concomitants of HIV/AIDS risk behaviours and intention to engage in risk behaviours in adolescents in India. AIDS CARE. 9: 563-576.

MNYIKA, KS; KLEPP, KI; KVALE, G; SCHREINER, A \& SEHA, AM 1997: Condom awareness and use in the Arusha and Kilimanjaro regions, Tanzania: a population-based study. AIDS Education and Prevention. 7: 403-414.

SHARMA, V; DAVE, S; SHARMA, A \& CHAUHAN, P 1997: Condoms: misuse=non-use: the condom equation in Gujarat, India. AIDS CARE. 9: 707-713.

WEBB, D 1997: HIV and AIDS in Africa. Cape Town: David Philip.
WORLD HEALTH ORGANISATION 1995: Condom promotion for AIDS prevention. Geneva: author.

ZAGUMMNY, MJ \& BRADY, DB 1998: Development of the AIDS Health Belief Scale (AHBS). AIDS Education and Prevention. 10: 173-179. 